
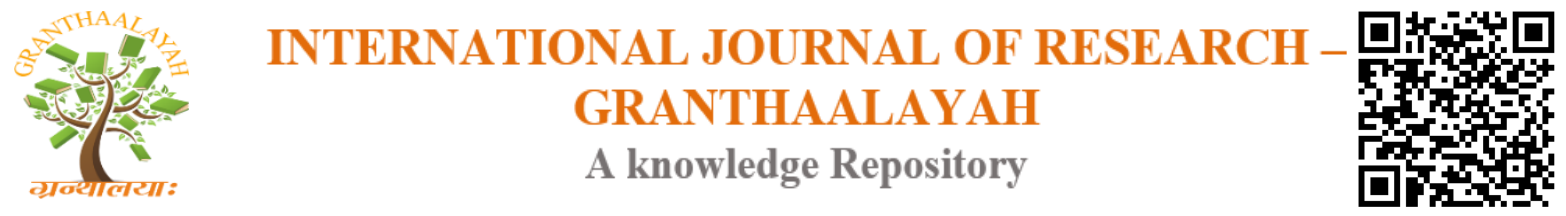

Social

\title{
CYBER CRIME IN BANKING SECTOR
}

\author{
Harshita Singh Rao *1 \\ ${ }^{* 1}$ Law Department, Indore Institute of Law, India
}

\begin{abstract}
With the headways in innovation, the Indian Managing an account Division has been at standard with the developing patterns and critical changes required in its tasks. The call for development has given this unit monstrous chances and therefore, banks are currently among the greatest recipients of the IT Insurgency. The multiplication in online exchanges mounting on advancements like NEFT (National Electronic Store Exchange), RTGS (Constant Gross Settlement), ECS ( Electronic Clearing Administration) and portable exchanges is a look at the profound established innovation in saving money and budgetary issues. Be that as it may, similar to opposite sides to a coin, openings accompany dangers and achievement accompanies its equal difficulties. Consequently, with the quick development of PCs and web innovation, new types of overall violations known as 'Digital Wrongdoings' has advanced in the scene. Over some undefined time frame, the nature and example of Digital Wrongdoing occurrences have turned out to be progressively modern and complex. Banks and Money related Foundations remain the unabated focuses of digital culprits in the most recent decade. Prominently monetary profit is as yet the real inspiration driving most cybercriminal exercises and there is minimal shot of this changing soon. This paper centers around the specialized parts of different kinds of cybercrimes concerning the saving money units and their related effects. Furthermore, it recognizes the danger vectors supporting these wrongdoings and creates measures to help in battling the subsequent digital assaults with the goal that such assaults can be better avoided later on for improved security.
\end{abstract}

Keywords: Digital Wrongdoing; Money Related Extortion Misrepresentation Location; Data fraud.

Cite This Article: Harshita Singh Rao. (2019). "CYBER CRIME IN BANKING SECTOR." International Journal of Research - Granthaalayah, 7(1), 148-161. https://doi.org/10.29121/granthaalayah.v7.i1.2019.1043.

\section{Introduction}

\subsection{Meaning of The Term "Cyber Crime"}

Until mid-1990s, managing an account segment in many parts of the world was basic and dependable; anyway since the coming of innovation, the keeping money division saw a change in perspective in the wonder. Banks so as to upgrade their client base presented numerous stages 
through which exchanges should be possible absent much exertion. These advancements empowered the client to get to their bank funds $24 * 7$ and year around through, ATMs and Web based managing an account methods.

Nonetheless, with the upgrade in innovation, keeping money cheats have additionally expanded similarly. Digital offenders are utilizing diverse intends to take one s bank data and at last their cash also.

It is in this manner, an aggregate agreement of banks and controllers to make arrangements and embrace measures so as to shield saving money stages from digital dangers. Various specialized guard and control estimates like expanded continuous supervision on exchanges have been attempted by the banks, nonetheless, even today the issue holds on. The explanation for this is the resistance measures right now accessible with banks are regularly receptive, tedious and accessible out in the open area which can be gotten to even by the digital criminal who thus receives measures to battle from these safeguards. The assailants allot their time in growing new methods for digital wrongdoing and furthermore at the same time take a shot at finding the answers for extension these protection measures.

One of the approaches to relieve the issue of digital wrongdoings in keeping money segment is to distinguish the variables identified with banks that are by and large focuses of such digital assaults, and why a few banks have never confronted such a circumstance. Banks which are for the most part focuses of digital wrongdoings experience the ill effects of different malware assaults in type of web based phishing, keystroke-loggings malwares, wholesale fraud, and so forth.

\subsection{Cyber Crime in Banking Sector}

Digital Wrongdoing can be just expressed as violations that include the utilization of PC and a network ${ }^{1}$ as a medium, source, instrument, target, or place of a wrongdoing. With the developing part of web based business and e-exchanges, the financial wrongdoing has floated towards the advanced world. Digital wrongdoings are expanding all around and India also has been seeing a sharp increment in digital violations related cases in the ongoing years.

In 2016, an investigation by Juniper Exploration evaluated that the worldwide expenses of cybercrime could be as high as 2.1 trillion by $2019 .{ }^{2}$ Anyway such gauges are just characteristic and the real expense of cybercrime including unreported harms is incalculable.

Digital Violations can be comprehensively arranged into classifications, for example, digital fear based oppression, Digital harassing, PC Vandalism, Programming Robbery, Wholesale fraud, Online Robberies and Fakes, Email Spam and Phishing and some more.

Nonetheless, from the part of money related digital wrongdoings submitted electronically, the accompanying classifications are transcendent:

\footnotetext{
${ }^{1}$ Kharouni, L. (2012). Automating Online Banking Fraud Automatic Transfer System: The Latest Cybercrime Toolkit Feature (Rep.).

${ }^{2}$ Liu, J., Hebenton, B., \&Jou, S. (n.d.). Handbook of Asian Criminology.
} 
- Hacking: It is a system to increase unlawful access to a PC or system so as to take, degenerate, or misguidedly see information.

- Phishing: It is a procedure to acquire private data, for example, usernames, passwords, and charge/Master card subtleties, by imitating as a reliable substance in an electronic correspondence and replay similar subtleties for pernicious reasons.

- Vishing: It is the criminal routine with regards to utilizing social designing via phone framework to access private individual and budgetary data from the general population with the end goal of monetary reward. ${ }^{3}$

- E-mail Satirizing: It is a procedure of concealing an email's real starting point by fashioned the email header to seem to begin from one real source rather than the real beginning source.

- Spamming: Undesirable and spontaneous messages typically sent in mass trying to constrain the message on individuals who might not generally get it are alluded to as Spam Messages.

- Denial of Administration: This assault is described by an express endeavor by aggressors to forestall real clients of an administration from utilizing that benefit by "flooding" a system to forbid real system traffic, upset associations between two machines to deny access to an administration or keep a specific individual from getting to an administration. ${ }^{4}$

- Advanced Constant Danger: It is portrayed as a lot of intricate, covered up and progressing PC hacking forms, frequently focusing on an explicit element to break into a system by keeping away from location together delicate data over a critical timeframe. The assailant generally utilizes some kind of social designing, to access the focused on system through authentic methods.

- ATM Skimming and Purpose of Offer Wrongdoings: It is a method of trading off the ATM machine or POS frameworks by introducing a skimming gadget on the machine keypad to show up as a veritable keypad or a gadget made to be fastened to the card peruser to resemble a piece of the machine. Furthermore, malware that takes Visa information specifically can likewise be introduced on these gadgets. Effective execution of skimmers cause in ATM machine to gather card numbers and individual distinguishing proof number (Stick) codes that are later repeated to complete fake exchanges.

\subsection{Internet Banking in India}

Electronic Keeping money or e-managing an account alludes to a framework where saving money exercises are completed utilizing instructive and PC innovation over human asset. In contrast with customary saving money administrations, in e-managing an account there is no physical association between the bank and the clients. E-managing an account is the conveyance of bank's data and administrations by banks to clients by means of various conveyance stages that can be utilized with various terminal gadgets, for example, PC and a cell phone with program or work area programming, phone or advanced TV. ${ }^{5}$

\footnotetext{
${ }^{3}$ Threats to the Financial Services sector (Rep.). (2014). Price water house Coopers.

${ }^{4}$ Net Losses: Estimating the Global Cost of Cybercrime (Rep.). (2014). Intel Security.

${ }^{5}$ Daniel, E. (1999), Provision of electronic banking in the UK and the Republic of Ireland, International Journal of Bank Marketing, Vol. 17, No. 2, pp. 72-82.
} 
The main activity in the territory of bank computerization was stemmed out of two progressive Boards on Computerization (Rangarajan Panel). ${ }^{6}$ The primary board of trustees was set up in 1984 which drew the outline for the automation and computerization in managing an account industry. The second Board of trustees was set up in 1989 which made ready for incorporated utilization of broadcast communications and PCs for applying completely the innovative leaps forward to the managing an account tasks. The center moved from the utilization of Cutting edge Record Posting Machines (ALPMs) for constrained computerization to full computerization at branches and to combination of the branches. ${ }^{7}$ Till 1989, banks in India had 4776 ALPMs at the branch level, more than 2000 software engineers/frameworks staff and more than 12000 Information Passage Terminal Administrators. ${ }^{8}$

The RBI established a Working Gathering on web Managing an account. In light of the idea of access to the managing an account items and administrations, the gathering partitioned web keeping money into three frameworks. ${ }^{9}$

1) Enlightening Framework This framework expects banks to give data about financing costs, credit plans, branch areas and so on to the clients. The client can download different kinds of utilization according to the necessities. Additionally clients are not required to uncover their personality and there is no sensible possibility of any unapproved individual getting into the creation arrangement of the bank. ${ }^{10}$

2) Open Framework This framework gives data to the client about his record balance, exchange subtleties and so on. The clients can look for the data after confirmation and signing in through the passwords. ${ }^{11}$

3) Value-based Framework In this framework a bank enables its clients to embrace exchanges through its framework and they are straightforwardly transferred to the client's record. There is bi-directional exchange that happens between the bank and the client and between the client and the outsider. This framework is anchored through security instruments like http and https. E-keeping money is otherwise called Digital Saving money, Home Saving money and Virtual Saving money. E-keeping money incorporates Web Saving money, Portable Managing an account, RTGS, ATMs, Mastercards, Charge cards, and Keen Cards and so forth. ${ }^{12}$

${ }^{6}$ Committees on Computerization, available at: https://www.rbi.org.in/Scripts/PublicationsView.aspx?id=162 (Last Visited: Dec. 10, 2018, 01:20 PM).

${ }^{7}$ Dr. B R Sharma and Dr. R P Nainta, Banking Law \& Negotiable Instruments Act, 4th Edn, Allahabad Law Agency, p 183.

8 Talwar S P, (1999), National Seminar on Computer Related Crime, Inaugural address by Shri S P Talwar, Deputy Governor, Reserve Bank of India, February 24, 1999.

${ }^{9}$ Reserve Bank of India, Report on Internet Banking, available at: https://www.rbi.org.in/Scripts/PublicationReportDetails.aspx?UrlPage=\&ID=243\#ch2 (Last Visited: Dec 11, 2018, 10:25 AM).

${ }^{10}$ Ibid.

11 Ibid.

${ }^{12}$ Dheenadhayalan V., Automation of Banking sector in India, Yojana, February, (2010) p.32. 


\subsection{Reasons for Cyber Crime}

Hart in his work, "the idea of law" has said 'people are helpless so standard of law is required to ensure them'. Applying this to the internet we may state that PCs are powerless so standard of law is required to secure and protect them against digital wrongdoing. The followings are a few reasons,

1) Capacity to store information in nearly little space

2) Easy to access

3) Complex

4) Negligence

5) Loss of proof

\subsection{Impact of Cyber Crime on Banking Sector}

The cases identified with cybercrimes have become savagely because of the upsurge in cell phones with web availability. Cell phones are these days utilized for various online exercises like web saving money, web based shopping, paying service charges and are continually according to the culprits to acquire access to private data.

Among the different inspirations for perpetrating a cybercrime, Monetary profit remains the consistent victor for the past numerous years surpassing different thought processes including requital, coercion and political causes. (Figure 3)

\begin{tabular}{l|r} 
Cyber Crimes by 'Motive' in 2014 & \multicolumn{2}{|c}{ Cases } \\
\hline Motive & 1736 \\
\hline Greed / Financial Gain & 599 \\
Insult to modesty of Women & 495 \\
Fraud/Illegal Gain & 357 \\
Sexual Exploitation & 285 \\
Personal Revenge / Settling scores & 272 \\
Causing Disrepute & 199 \\
Extortion & 174 \\
Inciting hate crimes Against Community & 159 \\
Motives of Blackmailing & 139 \\
Emotional motives like Anger, Revenge, etc & 110 \\
Prank / Satisfaction of Gaining Control & 82 \\
For developing own Business/Interest & 75 \\
Political Motives & 52 \\
For spreading Piracy & 27 \\
Sale/ Purchase of Illegal Drugs/Items & 25 \\
Disrupt Public Services & 11 \\
Inciting hate crimes Against Country & 3 \\
Steal Information for Espionage & \\
\hline Others*4816 & \\
&
\end{tabular}

Figure 3: CYBER CRIME BY MOTIVES 
Alarmingly, straightforward phishing assaults appreciate a triumph rate of $45 \%$ because of absence of mindfulness in regards to the normal shields to ensure against the savvy digital crooks.

The range of cybercrime can be assessed from the figures of 3855 cybercrimes carried out for monetary profit (NTRO) and 534 phishing occurrences (CERT-In) in year 2014. These episodes just relate to the detailed occurrences and don't involve the occurrences that went unreported or potentially unnoticed.

Banks over the globe are expanding getting to be practical objectives of conveyed forswearing ofbenefit (DDoS) assaults propelled some of the time as a piece of the arrangement to divert the security professional's thoughtfulness regarding the draining assets, while doing some extra unsafe action in parallel like addition of malware, or messing with the IT resources. Such an implanted hacking effort with a concealed plan is typically alluded to as Cutting edge Constant Danger and is the most recent child on the board with improved multifaceted nature and adroitness.

In the cases, where the aggressors are not ready to yield some significant data, they ruin the banks site as a measure to render retribution against their fizzled endeavors.

Other than the subsequent monetary benefits from fruitful digital assaults, the nearness of online illicit businesses generally alluded to as the 'Darkweb' ${ }^{13}$ adds to the inspiration of perpetrating cybercrimes as a typical for trading individual data, most recent endeavors and refined hacking units. Touchy data including stolen/spilled Master card numbers, web based managing an account accounts, therapeutic records and authoritative access to servers are exchanged for cash in these online extortion networks.

\section{Material and Methods}

The present review in light of optional information as it were. Optional information are gathered from different sources like magazine, Government report. Vast measure of optional information is accessible in the types of articles, manuals and beforehand directed analysts on the comparative theme. The information assembled will help in distinguishing key parameters to look at through further investigation and in this manner will help in characterizing the destinations of the examination.

\section{Case Study}

\subsection{Case Under the Study: (Examples) Official Website of Maharastra Government Hackedmumbai}

20 September 2007 - IT specialists were attempting yesterday to reestablish the official site of the administration of Maharashtra, which was hacked in the early long periods of Tuesday. Rakesh Maria, joint chief of police, said that the state's IT authorities stopped a formal objection with the Digital Wrongdoing Branch police on Tuesday. He included that the programmers would be found.

\footnotetext{
${ }^{13}$ Murashbekov, O B. (2015). Methods for Cybercrime Fighting Improvement in Developed Countries. Journal of Internet Banking and Commerce.
} 
Recently the site, http://www.maharashtragovernment.in, stayed blocked. Vice president Pastor and Home Priest R.R. Patil affirmed that the Maharashtra government site had been hacked. He included that the state government would look for its assistance and the Digital Wrongdoing Branch to examine the hacking. "We have taken a genuine perspective of this hacking, and if require be the legislature would even go further and look for the assistance of private IT specialists. Dialogs are in advancement between the authorities of the IT Office and specialists," Patil included. The state government site contains nitty gritty data about government offices, handouts, reports, and a few different subjects. IT specialists taking a shot at reestablishing the site disclosed to Middle Easterner News that they expect that the programmers may have decimated the majority of the site's substance. As indicated by sources, the programmers might be from Washington. IT specialists said that the programmers had recognized themselves as "Programmers Cool AlJazeera" and asserted they were situated in Saudi Arabia. They included this may be a red herring to divert specialists from their trail. As per a senior authority from the express government's IT division, the official site has been influenced by infections on a few events before, however was never hacked. The authority included that the site had no firewall. Three individuals held liable in on line Visa trick Clients Visa subtleties were abused through online methods for booking airtickets. These guilty parties were gotten by the city Digital Wrongdoing Examination Cell in Pune. It is discovered that subtleties abused were having a place with 100 individuals. Mr. Parvesh Chauhan, ICICI Prudential Extra security officer had griped for the benefit of one of his client. In such manner Mr. Sanjeet Mahavir Singh Lukkad, Dharmendra Bhika Kale and Ahmead Sikandar Shaikh were captured. Lukkad being utilized at a private foundation, Kale was his companion. Shaiklh was utilized in one of the parts of State Bank of India. As indicated by the data given by the police, one of the clients got a SMS based alarm for buying of the ticket notwithstanding when the Master card was being held by him. Customer was caution and came to realize something was fishy; he enquired and came to know about them isuse. He reached the Bank in such manner. Police watched association of numerous.

Banks in this reference - The tickets were book through online methods. Police asked for the log subtleties and got the data of the Private Establishment. Examination uncovered that the subtleties were gotten from State Bank of India. Shaikh was working in the Visa division; because of this he approached charge card subtleties of a few clients. He gave that data to Kale. Kale consequently passed this data to his companion Lukkad. Utilizing the data acquired from Kale Lukkad booked tickets. He used to pitch these tickets to clients and get cash for the equivalent. He had given couple of tickets to different establishments. Digital Cell head DCP Sunil Pulhari and PI Mohan Mohadikar A.P.I Kate were associated with eight days of examination lastly got the offenders. In this respects different Banks have been reached; additionally, four carrier businesses were reached. DCP Sunil Pulhari has asked for clients who have fallen in to this snare to advise police experts on 2612-4452 or 2612-3346 on the off chance that they have any issues.

UTI Bank snared in a phishing attack(14 February 2007) Fraudsters of the internet have raised its revolting head, the first of its sort in the year 2007, by propelling a phishing assault on the site of Ahmedabad-based UTI Bank, a main private bank advanced by India's biggest budgetary organization, Unit Trust of India (UTI).A URL on Geo Cities that is just about a copy form of the UTI Bank; s landing page is accounted for to flow among email clients. The website page not just requests the record holder's data, for example, client and exchange login and passwords, it has additionally beguilingly set up disclaimer and security peril articulations. On the off chance that 
you have gotten any email from a deliver having all the earmarks of being sent by UTIBANK, educating you concerning any progressions made in your own data, account subtleties or information on your client id and secret phrase of your net managing an account office, kindly don't react. It is UTI Bank policy not to look for or send such data through email. In the event that you have effectively uncovered your secret word please transform it quickly, the notice says. The dubious connection is accessible on http://br.geocities/If any clueless record holder enters his login id, secret phrase, exchange id and secret phrase so as to change his subtleties as exhorted by the bank, a similar information is sent vide mailform.cz (the phishes database). After examination, we found that Mail shape is an administration of PC Svet, which is a piece of the Czech organization PES Counseling. The Website admin of the webpage is an individual named PetrStastny whose email can be found on the site page. Top authorities at UTI Bank said that they have revealed the case to the Monetary Office Wing, Delhi Police. The bank has additionally drawn in the administrations of Melbourne-based Extortion Watch Worldwide, a main antiphishing organization that offers phishing checking and bring down arrangements. We are currently during the time spent shutting the site. A portion of these activities require significant investment, however clients have been kept on the up and up about these activities, said V K Ramani, President - IT, UTI Bank according to the discoveries of UTI Bank's security office, the phishers have sent in excess of 1,00,000 messages to account holders of UTI Bank and also different banks. Despite the fact that the organization has commenced harm control activities, none of the activities are penny percent idiot proof. Presently there is no chance to get for banks to know whether the individual signing in with exact client data is a cheat, said Ramani. In any case, dependable sources inside the bank and security offices affirmed that the misfortunes because of this specific assault were nada. The bank has sent alarms to every one of its clients illuminating about such malignant sites, other than expanding their caution and extortion reaction framework; Drawing in expert organizations like Misrepresentation Watch help in decreasing time to react to assaults; said Sanjay Haswar, Right hand VP, System and Security, UTI Bank.

\subsection{Case Study: India's First Atm Card Fraud}

The Chennai city police have busted a universal posse associated with digital wrongdoing, with the capture of Deepak prem manwani (22), who was caught in the act while breaking into an ATM in the city in June last, it is dependably learnt. The elements of the city cops' accomplishment can be ganged from the way that they have gotten a man who is on the needed rundown of the considerable FBI of the US. At the season of his detainment, he has with him Rs 7.5 lakh knocked off from two ATMs in T Nagar and Abiramipuram in the city. Preceding that, he has left with Rs 50,000 from an ATM in Mumbai.

While researching Manwani's case, the police discover a digital wrongdoing including scores of people over the globe.

Manwani is a MBA drop-out from a pune school and filled in as a promoting official in a Chennaibased firm for quite a while.

Strikingly, his daring wrongdoing profession began in a web bistro. While perusing the net one day, he got pulled in to a sire which offered him help with breaking into the ATMs. His contacts, sitting some place in Europe, were prepared to give him charge card number of a couple of 
American banks for $\$ 5$ per code. This site likewise offered the attractive codes of those cards, however charged $\$ 200$ per code. The administrator of the site has concocted an interesting plan to get the individual ID number (Stick) of the card clients. They skimmed another site which looked like that of a presumed telecom organizations.

That organization has a huge number of supporters. The phony site offered the guests to return $\$ 11.75$ per head which, the site advertisers stated, has been gathered in overabundance unintentionally from them. Trusting that it was an authentic offer the telecom organization being referred to, a few lakh supporters signed on to the site to get back that minimal expenditure, yet in the process separated with their PINs.

Outfitted with every single essential datum to hack the bank ATMs, the posse began its orderly plundering. Evidently, manwani and numerous others of his kind went into an arrangement with the pack behind the site and could buy any measure of information, obviously on specific terms, or basically go into an arrangement on a goods sharing premise.

In the interim, manwani additionally figured out how to create 30 plastic cards that contained important information to empower him to break into ATMs.

He was enterprising to the point that he had the capacity to offer away a couple of such cards to his contacts in Mumbai. The police are vigilant for those people as well.

On receipt of huge scale protestations from the charged Visa clients and bank in the US, the FEI began an examination concerning the undertaking and furthermore alarmed the CBI in New Delhi that the universal pack has built up a few connections in India as well.

Manwani has since been developed safeguard after cross examination by the CBI. In any case, the city police trust this is the start of the finish of a noteworthy digital wrongdoing.

\section{Findings}

Greater part of the cybercrimes in this segment have come about out of hacking and data fraud.

- Banks are being focused again and again on the grounds that every one of the stores as money are held with the banks.

- The security of the clients is at a colossal hazard since it has turned out to be anything but difficult to hack their own subtleties.

- The product utilized for recognizing fakes as a rule is either obsolete or extremely tedious.

- The quantity of cases fathomed by the digital cell has remained reliably low throughout the previous four years, with just 20 percent achievement rate.

There is no explicit order that bargains with these violations, specifically with the Saving money Segments. 


\section{Suggestions}

1) As there is no explicit requirement identified with the law, the significant effect of these violations is left unsolved numerous multiple times, a demonstration must be authorized to control this sort of danger.

2) The law implementation ought to be extremely unbending, and refreshed occasionally to monitor such wrongdoings.

3) There ought to be quick track portable courts to explain these cases, to meet the complaints and fabricate certainty among the general population.

4) The legislature ought to likewise keep a track on the working system exercises with the assistance of Huge Information Banks.

5) Disciplines and punishments should be practiced completely so as to limit the effect of these issues and punish the assailants.

6) Mindfulness Projects ought to be started so as to educate the general population about the continuous situation and forthcoming dangers.

7) General society should report these cases to the Digital Wrongdoing Branch in the issues related as opposed to simply alluding it to the banks, to guarantee quick and strict activities.

\section{Conclusion}

The investigation has given an outline to the idea of E-saving money by talking about profoundly different digital wrongdoings, distinguished explicitly in the managing an account division. The Saving money framework is the soul and spine of the economy. Data Innovation has turned into the foundation of the saving money framework. It gives an enormous help to the regularly expanding difficulties and managing an account necessities. By and by, banks can't consider presenting money related item without the nearness of Data Innovation. Anyway Data Innovation has an unfavorable effect too on our managing an account division where wrongdoings like, phishing, hacking, falsification, bamboozling and so on are submitted. There is a need to avert digital wrongdoing by guaranteeing validation, recognizable proof and check procedures when an individual goes into any sort of saving money exchange in electronic medium. The development in digital wrongdoing and intricacy of its examination strategy requires proper measures to be embraced. It is basic to expand the collaboration between the partners to handle digital wrongdoing. As indicated by National Wrongdoing Records Agency it was discovered that there has been a tremendous increment in the quantity of digital violations in India in recent years. Electronic wrongdoing is a difficult issue. In instances of digital wrongdoing, there isn't just money related misfortune to the banks yet the confidence of the client upon banks is additionally undermined. Indian managing an account division can't abstain from keeping money exercises helped out through electronic medium as the investigation recommend that there has been an expansion in the quantity of installments in e-saving money. Nonetheless, the adjustment in the saving money industry must be such which suits the Indian market. In conclusion, it very well may be presumed that to dispense with and kill cybercrime from the internet is certifiably not an apparently conceivable assignment however it is conceivable to have an ordinary keep an eye on managing an account exercises and exchanges. The main auspicious advance is to make mindfulness among individuals about their rights and obligations and to additionally making the usage of the laws all the more firm and stringent to check wrongdoing. 


\section{Recommendations}

Managing an account segment is the foundation of our economy. The expanding number of digital wrongdoing cases has brought about gigantic loses to our economy. Digital assaults ought to be averted by guaranteeing appropriate enactment which is actualized adequately. Both the banks and the client ought to be made mindful about the hazard included and shield measures. There should be collaboration between the different partners to counter digital wrongdoing. The Indian Government set up an Entomb Departmental Data Security Team (ISTF) with the National Security Board as the nodal organization for the coordination of all issues identifying with viable usage of its digital security technique. Indian PC Crisis Reaction Group (CERT-In) is the national nodal office which is made to react to PC security episodes at whatever point they happen. Maybe a couple of the exercises embraced by CERT in executing digital security incorporate coordination of reactions to security occurrences and other significant occasions; issuance of warnings and time bound exhortation in regards to unavoidable dangers; item vulnerabilities examination; directing trainings on particular points of digital security; and advancement of security rules on real innovation stages. ${ }^{14}$

One of the primary issues related with digital wrongdoing is of purview. Digital wrongdoing can be submitted in any piece of the globe having its effect in any corner. Each resident ought to have the capacity to recognize and report cybercrimes from anyplace paying little heed to the nation they live in. The current frameworks present in India for revealing digital related offenses includes enlisting dissensions with the neighborhood police headquarters or cybercrime cells. Numerous Indian states have setup cybercrime cells, which screen such wrongdoings. In a few occasions, where the casualties of cybercrime will most likely be unable to report a cybercrime because of a few reasons, for example, remaining in a remote area, ignorance in regards to the place to report and protection related issues. This will in general outcome in numerous cybercrime cases going unreported. Since, there is no unified online cybercrime announcing instrument. Likewise for law authorization offices at different dimensions, for example, national, state, and nearby dimension, there is no incorporated referral component for objections identifying with cybercrime. ${ }^{15}$ IT Act ought to be revised as needs be to characterize cybercrime and furthermore indicate the situations where the Demonstration will have additional regional purview. The extent of the IT Demonstration should be widened to incorporate legitimate structure identifying with digital laws in India. The obligation of the middle people is unclear and must be made progressively unmistakable and express.

\section{Cyber Fraud Council in Banks}

At whatever point a digital extortion is carried out the unfortunate casualty should answer to the Digital Misrepresentation Gathering that must be set up by in every single bank to audit, screen research and report about digital wrongdoing. In the event that, such Committee does not take perform or declines to play out its obligation then an arrangement to record a FIR must be made. The issue to be brought before such gathering can be of any esteem. In any case, when the esteem

\footnotetext{
14 Strategic national measures to combat cyber-crime: Perspective and learnings for India, available at: http://www.ey.com/Publication/vwLUAssets/ey-strategic-national-measures-to-combat-cybercrime/\$FILE/eystrategic-national-measures-to-combat-cybercrime.pdf (Last Visited: Dec 11 2018, 10:32 AM).

15 Ibid.
} 
is high then the Committee will act quickly. RBI in its 2011 Report expressed that when bank fakes are of short of what one Crore then it may not be important to require the consideration of the Extraordinary Advisory group Board. ${ }^{16}$

\section{Education to Customer}

The client ought to be instructed and made mindful about different bank cheats and measures ought to be educated to them for security components with the goal that they don't fall prey as casualties of digital wrongdoing. On the off chance that a client is cognizant and report the matter of digital wrongdoing, in the underlying stage likewise occurrences of digital violations can be diminished. A client ought to be made mindful about the Rules and regulations of E-managing an account. It very well may be done through distributing it on the bank's site, distributing in the paper, through notices, by sending SMS cautions, through publication training and so on. On the off chance that a bank present any new strategy or there are any progressions which are required to be trailed by all banks according to RBI at that point, bank must educate the client through sends or by illuminating the client through phone. ${ }^{17}$ The mindfulness material ought to be opportune refreshed remembering the adjustments in the enactment and rules of RBI. ${ }^{18}$

\section{Training of Bank Employees}

Preparing and Introduction programs must be directed for the workers by the banks. The workers must be made mindful about misrepresentation counteractive action measures. It very well may be done through pamphlets or magazines tossing light on cheats related parts of banks by senior functionaries, setting up 'Customs in the working environment of the representatives, security tips being flashed on screen at the season of signing into Center Saving money arrangement programming, having talks on elements causing cybercrime and activities required to be embraced in taking care of them. Representatives who go past their honorable obligation to forestall digital fakes whenever compensated will likewise upgrade the work commitment.

\section{Strong Encryption-Decryption Methods}

E-managing an account exercises must be managed utilizing Secure Attachments Layer (SSL). It gives encryption connection of information between a web server and a web program. The connection ensures that the information stays secret and secure. According to India, we pursue topsy-turvy crypto framework which requires two keys, open and private, for encryption and unscrambling of information. ${ }^{19}$ For SSL association a SSL Authentication is required which is conceded by the suitable expert under IT Act, 2000. To guarantee security exchanges RBI proposed for Open Key Foundation in Installment Frameworks, for example, RTGS, NEFT, and Check Truncation Framework. As per RBI it would guarantee a safe, sheltered and sound arrangement of installment. ${ }^{20}$ Remote security arrangements ought to likewise be consolidated. In instances of Forswearing of Administration Assaults, banks ought to introduce and arrange organize security gadgets.

\footnotetext{
${ }^{16}$ Reserve Bank of India, Working Group on Information Security, Electronic Banking, Technology Risk Management and Cyber Frauds, (21 Jan 2011).

${ }^{17}$ Ibid.

${ }^{18}$ Ibid.

${ }^{19}$ Section 3(2), Information Technology Act, 2000 provides authentication of Electronic Records shall be effected by the use of asymmetric crypto system and hash function which envelop and transform the initial electronic record into another electronic record.

${ }^{20} \mathrm{RBI}$ for two stage verification for online banking transactions, Economic Times, Mumbai, April 22,2014.
} 


\section{Physical and Personnel Security}

Banks must execute legitimate physical and biological system controls offering respects to dangers, and dependent on the establishment's extraordinary geological area, and neighboring substances and so forth. Likewise, when another representative is utilized at that point there ought to be a procedure of check of the candidate. The dimension of confirmation may careful contingent on the position and occupation profile. ${ }^{21}$ In ATMs there must dependably be a security protect who has gotten legitimate preparing under the power. It is on the grounds that numerous occurrences happen where ATMs are plundered. So physical security at ATMs is important.

\section{Cooperation Among Nations to Avert Cybercrime}

The internet being transnational in nature requires collaboration among States to cooperate to turn away digital wrongdoing. In spite of the fact that, a couple of bargains and usage estimates exist; a healthy methodology characterizing legitimate and specialized measures and authoritative abilities is yet to take focal significance for India in its objective to add to the worldwide battle against cybercrime. IT Act, 2000 having additional regional application represents an issue in examination, arraignment and removal of outside nationals. India ought to effectively connect as a feature of the worldwide cybercrime network focused on Asia, Europe and America to look for help and furthermore add to universal cybercrime issues. ${ }^{22}$

\section{Acknowledgement}

I have put in efforts in this project. However, it would not have been possible without the kind support and help of many individuals and organizations. I would like extent my sincere thanks to all of them.

I thank my God for providing me with everything that I required in completing this project. I am highly indebted to the Teacher in Charge Mrs. Ishita Rana for guidance and constant supervision as well as for providing necessary information regarding the project and also for her support in completing the project.

I would like to express my gratitude towards my parents for their kind co-operation and encouragement which helped me in the completion of this project.

My hearty thanks and appreciations go to my classmates in developing the project and to the people who have willingly helped me out with their abilities.

\section{References}

[1] "Newsbank - The Sacramento Bee \& Sacbee.com".

[2] "What is Bank Fraud?". wiseGEEK.

[3] "Home - JPMorgan Chase \& Co".

[4] Bell, Alexis (2010). Mortgage Fraud \& the Illegal Property Flipping Scheme: A Case Study of United States v. Quintero-Lopez. Archived from the original on 2018-11-28.

\footnotetext{
${ }^{21}$ RBI Guidelines on Information Security, Electronic Banking, Technology Risk management and Cyber Frauds, 2012.

${ }^{22}$ Ibid.
} 
[5] "ATM deposit automation, ATM deposit processing, envelope-free deposits". Carreker.com.

[6] "New U.S. Birth Certificate Requirement". Bureau of Consular Affairs, U.S. Department of State.

[7] "Types of banking fraud | ANZ". www.anz.com.

[8] "Online fraud and scams - Australian Federal Police". www.afp.gov.au.

[9] "How Prime Bank Frauds Work". US Securities and Exchange Commission.

[10] Moore, R. (2005) "Cyber crime: Investigating High-Technology Computer Crime," Cleveland, Mississippi: Anderson Publishing.

[11] Warren G. Kruse, Jay G. Heiser (2002). Computer forensics: incident response essentials. AddisonWesley. p. 392. ISBN 0-201-70719-5.

[12] Jump up to:a b c * Halder, D., \& Jaishankar, K. (2011) Cyber crime and the Victimization of Women: Laws, Rights, and Regulations. Hershey, PA, USA: IGI Global. ISBN 978-1-60960-8309

[13] Steve Morgan (Nov. 17, 2018). "Cyber Crime Costs Projected To Reach \$2 Trillion by 2019". Forbes.

[14] "Cyber crime costs global economy \$445 billion a year: report". Reuters. 2014-06-09.

[15] "\#Cybercrime - what are the costs to victims - North Denver News". North Denver News.

[16] Lewis, James (DEC.2018). "Economic Impact of Cybercrime - No Slowing Down"(PDF).

[17] Gordon, Sarah. "On the definition and classification of cybercrime"(PDF).

[18] Laqueur, Walter; C., Smith; Spector, Michael (2002). Cyberterrorism. Facts on File. pp. 52-53.

[19] "Cybercriminals Need Shopping Money in 2017, Too! - SentinelOne". sentinelone.com.

[20] Lepofsky, Ron. "Cyberextortion by Denial-of-Service Attack" (PDF). Archived from the original (PDF) on NOV.6, 2018.

*Corresponding author.

E-mail address: harshitasinghrao@ gmail.com 